Case Report

\title{
A Rare Case of Perforated Descending Colon Cancer Complicated with a Fistula and Abscess of Left Iliopsoas and Ipsilateral Obturator Muscle
}

\author{
Alban Cacurri, ${ }^{1}$ Gaspare Cannata, ${ }^{1}$ Stefano Trastulli, ${ }^{2}$ Jacopo Desiderio, ${ }^{2}$ \\ Antongiulio Mangia, ${ }^{1}$ Olga Adamenko, ${ }^{2}$ Eleonora Pressi, ${ }^{2}$ Giorgio Giovannelli, ${ }^{2}$ \\ Giuseppe Noya, ${ }^{1}$ and Amilcare Parisi ${ }^{2}$ \\ ${ }^{1}$ Department of General and Oncologic Surgery, University of Perugia, 06157 Perugia, Italy \\ ${ }^{2}$ Department of Digestive and Liver Surgery Unit, St. Maria Hospital, 05100 Terni, Italy
}

Correspondence should be addressed to Gaspare Cannata; gaspare.cannata@libero.it

Received 20 November 2013; Accepted 9 February 2014; Published 16 March 2014

Academic Editors: F. Catena and A. Cho

Copyright (C) 2014 Alban Cacurri et al. This is an open access article distributed under the Creative Commons Attribution License, which permits unrestricted use, distribution, and reproduction in any medium, provided the original work is properly cited.

Perforation of descending colon cancer combined with iliopsoas abscess and fistula formation is a rare condition and has been reported few times. A 67-year-old man came to our first aid for an acute pain in the left iliac fossa, in the flank, and in the ipsilateral thigh. Ultrasonography and computed tomography revealed a left abdominal wall, retroperitoneal, and iliopsoas abscess that also involved the ipsilateral obturator muscle. It proceeded with an exploratory laparotomy that showed a tumor of the descending colon adhered and perforated in the retroperitoneum with abscess of the iliopsoas muscle on the left-hand side, with presence of a fistula and liver metastases. A left hemicolectomy with drainage of the broad abscess was performed. Pathologic report findings determined adenocarcinoma of the resected colon.

\section{Introduction}

Infections of the retroperitoneal space have troubled physicians in all disciplines for decades because of remarkable diagnosis and treatment problems along with a mortality rate which is around 20\% [1]. Retroperitoneal abscesses with no triggering cause are rare. In the past the most frequent were the "cold" ones as tuberculosis, whereas today the "hot" ones, secondary to Crohn's disease, pyelonephritis, and diverticulitis, are most frequent [2]. It is very rare that a retroperitoneal abscess, particularly in the iliopsoas muscle, is caused by a perforation of a cancer of the descending colon.

In fact colon cancer, which represents the most frequent tumor of the digestive tract [3], involves bleeding, perforative, and occlusive events among the most common complications; these latter ones are more suggestive of a tumor of the descending colon. Furthermore the invasion of adjacent organs can be found frequently in case of cancer of the left colon in an advanced stage like a T4 according to the TNM classification and staging of the 2010 [4]. But an event like the perforation with invasion of the abdominal wall and the possible formation of an abscess in the retroperitoneal space is relatively rare [5]. In cases where a colorectal cancer shows atypical clinical findings the diagnosis is very difficult; moreover, the delay of the diagnosis and the inadequate clinical management represent a major cause of an increase in morbidity and mortality [5-8].

Here is a case of cancer of the descending colon which was presented with an unusual abscess of the left iliopsoas muscle and ipsilateral obturator muscle.

\section{Case Report}

A 67-year-old man came to our first aid for an acute pain in the left iliac fossa, in the flank, and in the ipsilateral thigh. 


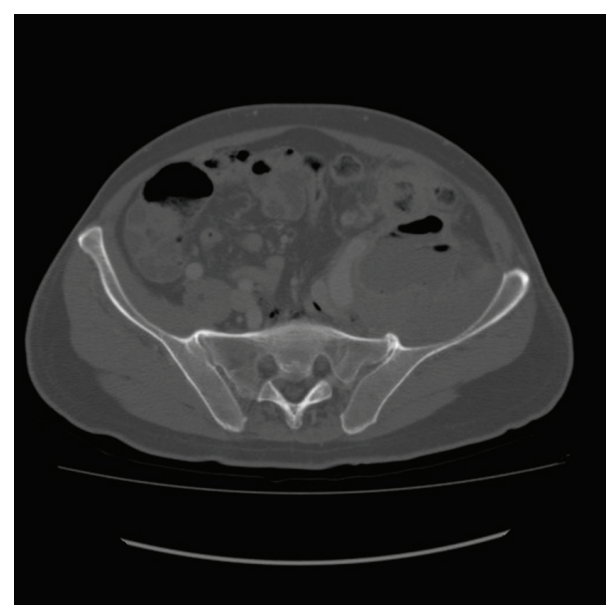

FIgURE 1

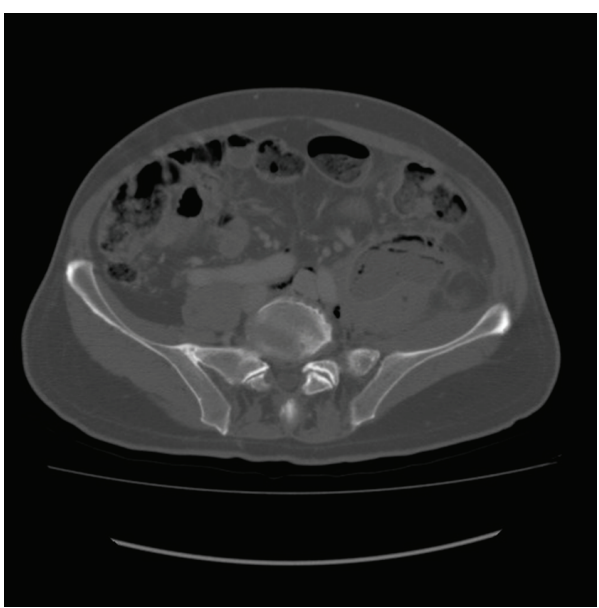

Figure 2
He had a 5-day history of pain in walking and in the left lower limb.

At ER the patient showed no pathological vital parameters, with the exception of a body temperature of $37.5^{\circ} \mathrm{C}$.

The physical examination showed an abdominal distension localized in left iliac fossa and flank. A deep painful mass of stretched-elastic consistency was palpated on the left lower quadrant, anything of relevance in the remaining abdominal quadrants. The sign of Blumberg was negative. The femoral wrists were present.

The clinical suspicion was a diverticulitis of sigma complicated by a perforation and peridiverticular abscess (Hinchey IIa-IIb). Then were performed laboratory hematobiochemical routine tests and we proceeded with diagnostic imaging: an abdominal ultrasound and CT with and without iodate contrast.

On admission in ER the following hematobiochemical values were altered: the WBC of $21.23 * 10^{3} / \mathrm{mm}^{3}$ (n.v. 4.50-10.80), with remarkable neutrophilia: $87.1 \%$ (n.v. $40.5-$ $74.1 \%$ ); C-reactive protein of $22 \mathrm{mg} / \mathrm{dL}$ (n.v. $<0.1 \mathrm{mg} / \mathrm{dL}$ ); the erythrocyte sedimentation rate of $35 \mathrm{~mm} / \mathrm{h}$ (n.v. 0-20 mm/h).

The abdominal ultrasonography showed a thickening of the colic walls in left flank-iliac fossa with hyperdense appearance of perivisceral fat and neighboring fluid. We proceed to a computerized axial tomography performed with and without iodate contrast. The CT (Figures 1 and 2) showed a liver increased in volume, with focal lesions of probable abscessual nature and a big abscess in the left psoas muscle, that appeared to be increased in volume and that also involved the ipsilateral obturator muscle.

So was performed an emergency intervention. It proceeded with an exploratory laparotomy which emphasized left dolichocolon. It showed a tumor of the descending colon adhered and perforated in the retroperitoneum with abscess of the iliopsoas muscle on the left-hand side, with presence of a fistula and liver metastases. So was performed a left hemicolectomy with tying of the mesenteric artery below the origin, removal of the tablet seat of peritoneal perforation, drainage of the broad abscess of the iliopsoas muscle, removal of the pus to culture examination, and the washing of the abscessual cavity with double drainage of the same. A metastasis surfacing the IV hepatic segment was asportated.

The culture examination of the abscessual liquid was positive for the following bacteria: Citrobacter braakii and Escherichia coli. After antibiogram, the patient was treated with adequate targeted antibiotic therapy. The results of histopathological examination of the removed colic mass confirmed the diagnosis of adenocarcinoma with the following TNM classifications [4]: T4 N2 M1 and G3, according to the grading drawn up by the WHO. The patient had a regular postoperative progress with resolution of symptoms and is currently undergoing adjuvant chemotherapy.

\section{Discussion and Conclusions}

The first abscess of the psoas was described by Mynter in 1881; he was talking about this clinical condition using the term "psoitis" [9]. In general, the abscesses of the psoas muscles can be classified into primary or secondary depending on the presence or not of an underlying pathology. The primary abscesses occur as a result of a spread by the hematogenic via of an infectious process (Table 1), while Crohn's disease represents the most common cause of secondary abscess of the psoas [10]. Other common secondary causes of abscess of the psoas muscles (Table 2) comprise more than Crohn's disease ( $60 \%$ of cases), the appendicitis (16\%), ulcerative colitis, and diverticulitis (11\%) [11]. In a review of 367 cases, Ricci et al. noticed a different etiology of the abscess of the psoas muscles depending on the geographical location [12]; in Asia and Africa more than 99\% of the psoas abscesses are primary, while in Europe and in North America primary abscesses are, respectively, $17 \%$ and $61 \%$ [12]. The iliopsoas abscess is more common in the young than in the elderly [13]. It was also reported to be more common in boys than in girls $[14,15]$. The mortality rate in primary iliopsoas abscesses is around $2.4 \%$, while $19 \%$ in secondary abscesses [16], although 
TABLE 1: Primary iliopsoas abscess can occur in [17].

Intravenous drug abuse

Diabetes mellitus

AIDS

Renal failure

Immunosuppression

TABLE 2: Conditions associated with secondary iliopsoas abscess [18].

\begin{tabular}{|c|c|}
\hline Gastrointestinal & Crohn's disease, diverticulitis, and appendicitis \\
\hline Genitourinary & $\begin{array}{l}\text { Urinary tract infection, cancer, and } \\
\text { extracorporeal shock wave lithotripsy }\end{array}$ \\
\hline Musculoskeletal & $\begin{array}{l}\text { Vertebral osteomyelitis, septic arthritis, } \\
\text { infectious, and sacroiliitis }\end{array}$ \\
\hline Vascular & $\begin{array}{l}\text { Infected abdominal aortic aneurysm, femoral } \\
\text { vessel, and catheterisation }\end{array}$ \\
\hline Miscellaneous & $\begin{array}{l}\text { Endocarditis, intrauterine contraceptive } \\
\text { device, and suppurative lymphadenitis }\end{array}$ \\
\hline
\end{tabular}

Ricci et al. suggest that the mortality rate in untreated patients reaches $100 \%$ [12].

A recent study carried out in Taiwan shows a frequency of abscesses of the psoas muscle of 2.5 cases per year [19]. In the past, the psoas abscess was mainly caused by tuberculosis of the spine (Pott's disease), but, with the decline of the prevalence of infections caused by mycobacterium tuberculosis, the main pathogens associated with the abscesses of the psoas muscles are those that are related to the diseases of the digestive tract. While the primary abscesses are caused in about $88 \%$ of the cases by Staphylococcus aureus [12], the secondary abscesses of the iliopsoas are caused by Streptococcus species in $4.9 \%$ of the cases and E. coli in $2.8 \%$ [12].

A relatively rare event (Table 3 ) is instead the abscessual formation of the psoas muscle caused by perforation of a colon cancer (Table 4) with an incidence estimated between 0.3 and $0.4 \%$ [20], while the perforation incidence of the cancer colon varies from 3 to $10 \%$ [21].

The psoas muscles abscess by perforation of the descending colon cancer may arise or be less with a fistula, in about $15 \%$ of the cases [28]. In our case the abscess and the fistula were present. Michowitz et al. proposed a clinical classification of complicated perforations by colon cancer that can be divided into (1) free drilling with loss of intestinal material in peritoneal cavity; (2) drill covered with local training of an abscess; (3) perforation in a neighboring organ or formation of a fistula [29]. Even if the mechanism of formation of the abscess remains unclear, the loss of intestinal contents from perforated cancer may lead to different unusual clinical presentations as retroperitoneal, subcutaneous, and/or perinephric abscesses; perirectal abscesses and fistulas; acute appendicitis and appendicular abscess [30].
TABLE 3: Main clinical features of iliopsoas abscess [18].

Flank and/or back and/or abdominal pain

Fever

Limp

Malaise

Weight loss

Lump in the groin

An accurate preoperative diagnosis of abscess correlated with a perforated colon cancer is extremely complicated, but the execution of laboratory tests that evidence a marked leukocytosis and especially the use of an abdominal CT is very useful in the diagnosis, in a precise location, and in the determination of the boundaries of the lesion and the dissemination of the surrounding soft tissues. In our case, considering the results of laboratory and instrumental tests and considering the patient clinical condition of acute abdomen we decided for emergency intervention. During the exploratory laparotomy the presence of a malignant perforated cancer and the fistula was evaluated which fired the abscess at the level of the left iliopsoas muscle and ipsilateral obturator muscle. The patient improved greatly his clinical conditions as a result of the intervention that it is concluded with a left hemicolectomy accompanied by a drainage and subsequent repeated washing of the large retroperitoneal abscess and by the removal of the tablet peritoneal seat of the perforation and the fistula. The removal en bloc of colonic tumor of the fistula and the wall of the abscess allowed a better oncological efficiency of the intervention. After surgery a target antibiotic therapy, suggested by culture of abscessual liquid positive for E. coli and Citrobacter braakii, was set.

In conclusion we have treated a case of perforated adenocarcinoma of the descending colon with an unusual formation of an abscess of the left iliopsoas muscle with involvement of the ipsilateral obturator muscle with relative fistula. The accurate preoperative diagnosis of these conditions clinic is extremely complicated because of the fuzzy clinical presentation, despite the ongoing developments in the context of diagnostic imaging. The importance is to focus on the differential diagnosis and keep in mind that a colon carcinoma can lead to a similar clinical condition. In the collection of the history and during the objective exam, signs of the presence of an abscess are the fever, pain, the presence of a palpable mass, and leukocytosis. The use of the CT can be very useful, even if the definitive diagnosis of colic perforated neoplasia may be evident only during surgery. It is good to intervene as soon as possible in similar conditions with a colon resection affected by neoplasia, with the resection of the fistula (if present), and with the drainage of the abscess to reduce significantly the morbidity and mortality associated with this fearful condition. 
TABLE 4: Summary of some cases of colon cancer complicated with psoas abscess reported between 1990 and 2013.

\begin{tabular}{|c|c|c|c|c|c|c|c|}
\hline Case & Age/sex & Pathogen & Antibiotic & $\begin{array}{l}\text { Cancer } \\
\text { location }\end{array}$ & Management & Outcome & Reference \\
\hline 1 & $85 / \mathrm{F}$ & $\begin{array}{c}\text { Streptococcus, } \\
\text { Prevotella buccae, } \\
\text { and Bacteroides }\end{array}$ & IV fosfomycin & Right & LDOA & Recovery & Okita et al. [22] \\
\hline 2 & $27 / \mathrm{F}$ & E. coli & $\begin{array}{l}\text { IV 2nd and 3rd } \\
\text { generation } \\
\text { cephalosporin and } \\
\text { metronidazole }\end{array}$ & Left & $\mathrm{PD}$ & Recovery & Lee et al. [23] \\
\hline 3 & $67 / \mathrm{M}$ & E. coli and anaerobic bacteria & IV carbapenem & Left & PD then LDOA & Recovery & $\begin{array}{c}\text { Takakura et al. } \\
{[24]}\end{array}$ \\
\hline 4 & $44 / \mathrm{M}$ & $\begin{array}{l}\text { Streptococcus agalactiae } \\
\text { and Streptococcus anginosus }\end{array}$ & $\begin{array}{l}\text { IV ciprofloxacin and } \\
\text { metronidazole then IV } \\
\text { 3rd generation } \\
\text { cephalosporin and } \\
\text { metronidazole }\end{array}$ & Left & $\begin{array}{c}\text { Left hemicolectomy } \\
\text { and drainage of } \\
\text { abscess }\end{array}$ & Recovery & Yang et al. [25] \\
\hline 5 & $57 / \mathrm{M}$ & $\begin{array}{c}\text { Salmonella group B, } \\
\text { Bacteroides caccae, } \\
\text { Bacteroides fragilis, } \\
\text { and Peptostreptococcus indolicus }\end{array}$ & $\begin{array}{l}\text { IV ampicillin and } \\
\text { sulbactam }\end{array}$ & Bilateral & Bilateral PD & Recovery & Lo et al. [26] \\
\hline 6 & $76 / \mathrm{F}$ & E. coli and Proteus penneri & IV imipenem & Right & $\begin{array}{c}\text { PD then laparotomy } \\
\text { with right } \\
\text { hemicolectomy }\end{array}$ & Recovery & $\begin{array}{l}\text { Tsukuda et al. } \\
\text { [27] }\end{array}$ \\
\hline $\begin{array}{l}\text { Our } \\
\text { case }\end{array}$ & $67 / \mathrm{M}$ & E. coli and Citrobacter braakii & $\begin{array}{l}\text { Piperacillin/tazobactam } \\
+ \text { metronidazole }\end{array}$ & Left & $\begin{array}{l}\text { Laparotomy with left } \\
\text { hemicolectomy and } \\
\text { drainage of abscess }\end{array}$ & Recovery & \\
\hline
\end{tabular}

IV: intravenous; PD: percutaneous drainage; LDOA: laparotomy with drainage of the abscess.

\section{Conflict of Interests}

No potential conflict of interests relevant to this paper was reported.

\section{References}

[1] J. T. Crepps, J. P. Welch, and R. Orlando III, "Management and outcome of retroperitoneal abscesses," Annals of Surgery, vol. 205, no. 3, pp. 276-281, 1987.

[2] A. Martino, F. Catuogno, P. Festa et al., "Retroperitoneal abscess by suppurative psoas. Case report," Annali Italiani di Chirurgia, vol. 79, pp. 377-382, 2008.

[3] “Colorectal cancer," in World Cancer Report 2003, B. W. Stewart and P. Kleihues, Eds., pp. 198-202, HICP Press, Lyon, France.

[4] "AJCC: colon and rectum," in AJCC Cancer Staging Manual, S. B. Edge, D. R. Byrd, C. C. Compton, A. G. Fritz, F. L. Greene, and A. Trotti, Eds., pp. 143-164, Springer, New York, NY, USA, 7 th edition, 2010.

[5] D. D. T. Maglinte and H. M. Pollack, "Retroperitoneal abscess: a presentation of colon carcinoma," Gastrointestinal Radiology, vol. 8, no. 2, pp. 177-181, 1983.

[6] R. Cirocchi, S. Trastulli, I. Abraha et al., "Non-resection versus resection for an asymptomatic primary tumour in patients with unresectable stage IV colorectal cancer," Cochrane Database of Systematic Reviews, vol. 8, Article ID CD008997, 2012.

[7] R. Cirocchi, E. Farinella, S. Trastulli et al., "Safety and efficacy of endoscopic colonic stenting as a bridge to surgery in the management of intestinal obstruction due to left colon and rectal cancer: a systematic review and meta-analysis," Surgical Oncology, vol. 22, no. 1, pp. 14-21.

[8] R. Cirocchi, E. Farinella, S. Trastulli, F. Sciannameo, and R. A. Audisio, "Elective sigmoid colectomy for diverticular disease. Laparoscopic vs open surgery: a systematic review," Colorectal Disease, vol. 14, no. 6, pp. 671-683, 2012.

[9] H. Mynter, "Acute psoitis," Buffalo Medical and Surgical Journal, vol. 21, pp. 202-210, 1881.

[10] S. N. Agrawal, A. J. Dwivedi, and M. Khan, "Primary psoas abscess," Digestive Diseases and Sciences, vol. 47, no. 9, pp. 21032105, 2002.

[11] M. van den Berge, S. de Marie, T. Kuipers, A. R. Jansz, and B. Bravenboer, "Psoas abscess: report of a series and review of the literature," Netherlands Journal of Medicine, vol. 63, no. 10, pp. 413-416, 2005.

[12] M. A. Ricci, F. B. Rose, and K. K. Meyer, "Pyogenic psoas abscess: worldwide variations in etiology," World Journal of Surgery, vol. 10, no. 5, pp. 834-843, 1986.

[13] I. Gruenwald, J. Abrahamson, and O. Cohen, "Psoas abscess: case report and review of the literature," Journal of Urology, vol. 147, no. 6, pp. 1624-1626, 1992.

[14] M. Paley, P. S. Sidhu, R. A. Evans, and J. B. Karani, "Retroperitoneal collections-aetiology and radiological implications," Clinical Radiology, vol. 52, no. 4, pp. 290-294, 1997.

[15] R. Zissin, G. Gayer, E. Kots, M. Werner, M. Shapiro-Feinberg, and M. Hertz, "Iliopsoas abscess: a report of 24 patients diagnosed by CT," Abdominal Imaging, vol. 26, no. 5, pp. 533539, 2001.

[16] N. H. Qureshi, D. P. O'Brien, and D. A. Allcutt, "Psoas abscess secondary to discitis: a case report of conservative 
management," Journal of Spinal Disorders, vol. 13, no. 1, pp. 7376, 2000.

[17] T. R. Walsh, J. R. Reilly, E. Hanley, M. Webster, A. Peitzman, and D. L. Steed, "Changing etiology of iliopsoas abscess," American Journal of Surgery, vol. 163, no. 4, pp. 413-416, 1992.

[18] I. H. Mallick, M. H. Thoufeeq, and T. P. Rajendran, "Iliopsoas abscesses," Postgraduate Medical Journal, vol. 80, no. 946, pp. 459-462, 2004.

[19] J.-J. Huang, M.-K. Ruaan, R.-R. Lan, and M.-C. Wang, "Acute pyogenic iliopsoas abscess in Taiwan: clinical features, diagnosis, treatments and outcome," Journal of Infection, vol. 40, no. 3 , pp. 248-255, 2000.

[20] A. Rehman Alvi, Z. U. Rehman, and Z. U. Rehman G Nabi, "Pyogenic psoas abscess: case series and literature review," Tropical Doctor, vol. 40, no. 1, pp. 56-58, 2010.

[21] N. Mandava, S. Kumar, W. F. Pizzi, and I. J. Aprile, "Perforated colorectal carcinomas," American Journal of Surgery, vol. 172, no. 3, pp. 236-238, 1996.

[22] A. Okita, Y. Kubo, M. Tanada, A. Kurita, and S. Takashima, "Unusual abscesses associated with colon cancer: report of three cases," Acta Medica Okayama, vol. 61, no. 2, pp. 107-113, 2007.

[23] K. N. Lee, H. L. Lee, J. H. Yoon et al., "A case of mucinous adenocarcinoma of the colon presenting with psoas abscess," The Korean Journal of Gastroenterology, vol. 52, no. 2, pp. 120123, 2008.

[24] Y. Takakura, S. Ikeda, M. Yoshimitsu et al., "Retroperitoneal abscess complicated with necrotizing fasciitis of the thigh in a patient with sigmoid colon cancer," World Journal of Surgical Oncology, vol. 7, article 74, 2009.

[25] J.-Y. Yang, J.-K. Lee, S.-M. Cha, and Y.-B. Joo, "Psoas abscess caused by spontaneous rupture of colon cancer," Clinics in Orthopedic Surgery, vol. 3, no. 4, pp. 342-344, 2011.

[26] C.-H. Lo, Y.-S. Yang, and C.-L. Ho, "Rectal adenocarcinoma with bilateral psoas muscle abscess: case report and review of the literature," Journal of Medical Sciences, vol. 33, no. 4, pp. 225227, 2013.

[27] K. Tsukuda, E. Ikeda, T. Miyake et al., "Abdominal wall and thigh abscess resulting from the penetration of ascending colon cancer," Acta Medica Okayama, vol. 59, no. 6, pp. 281-283, 2005.

[28] C. M. Peterson, J. G. Allison, and C. C. Lu, "Psoas abscess resulting from perforating carcinoma of the sigmoid colon. Report of a case," Diseases of the Colon and Rectum, vol. 26, no. 6, pp. 390-392, 1983.

[29] M. Michowitz, D. Avnieli, I. Lazarovici, and M. Solowiejczyk, "Perforation complicating carcinoma of colon," Journal of Surgical Oncology, vol. 19, no. 1, pp. 18-21, 1982.

[30] A. P. Panwalker, "Unusual infections associated with colorectal cancer," Reviews of Infectious Diseases, vol. 10, no. 2, pp. 347-364, 1988. 


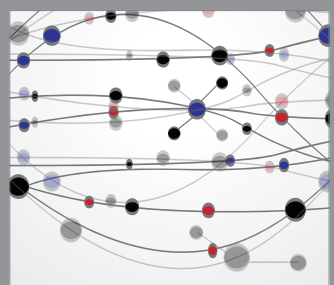

The Scientific World Journal
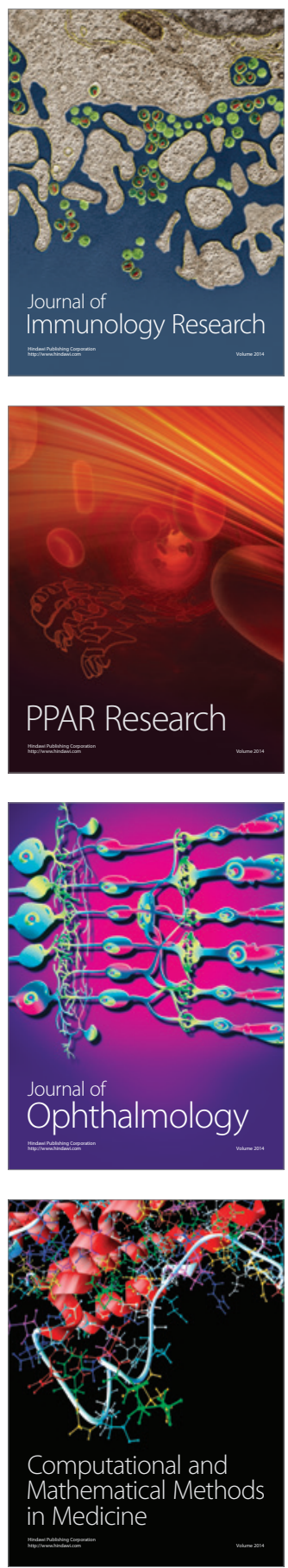

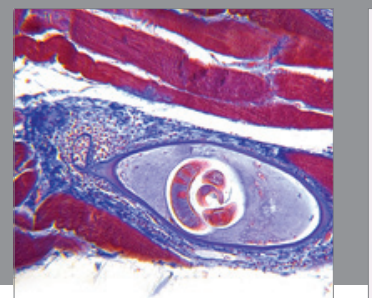

Gastroenterology

Research and Practice
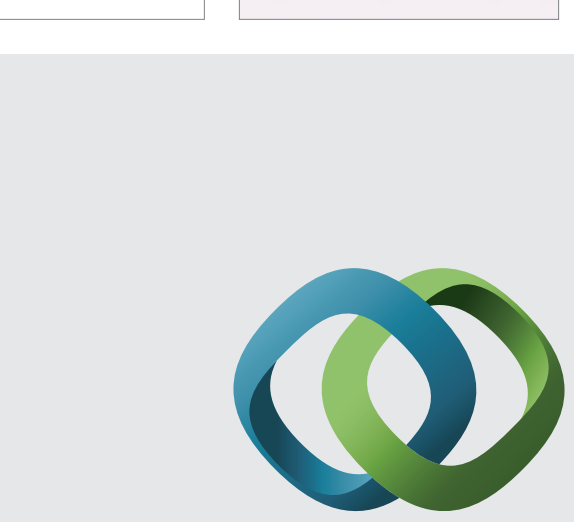

\section{Hindawi}

Submit your manuscripts at

http://www.hindawi.com
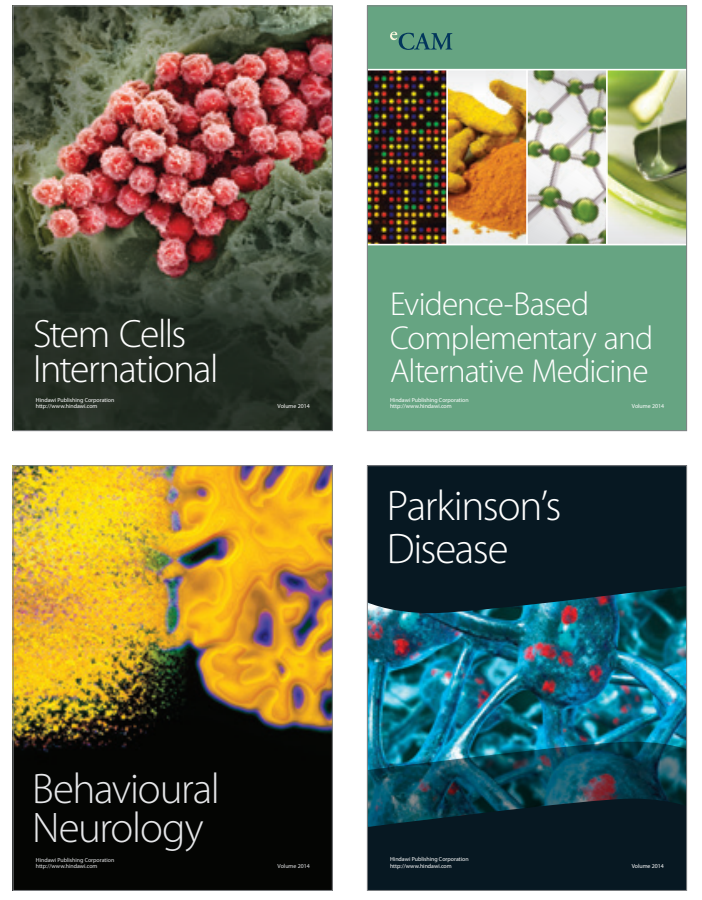
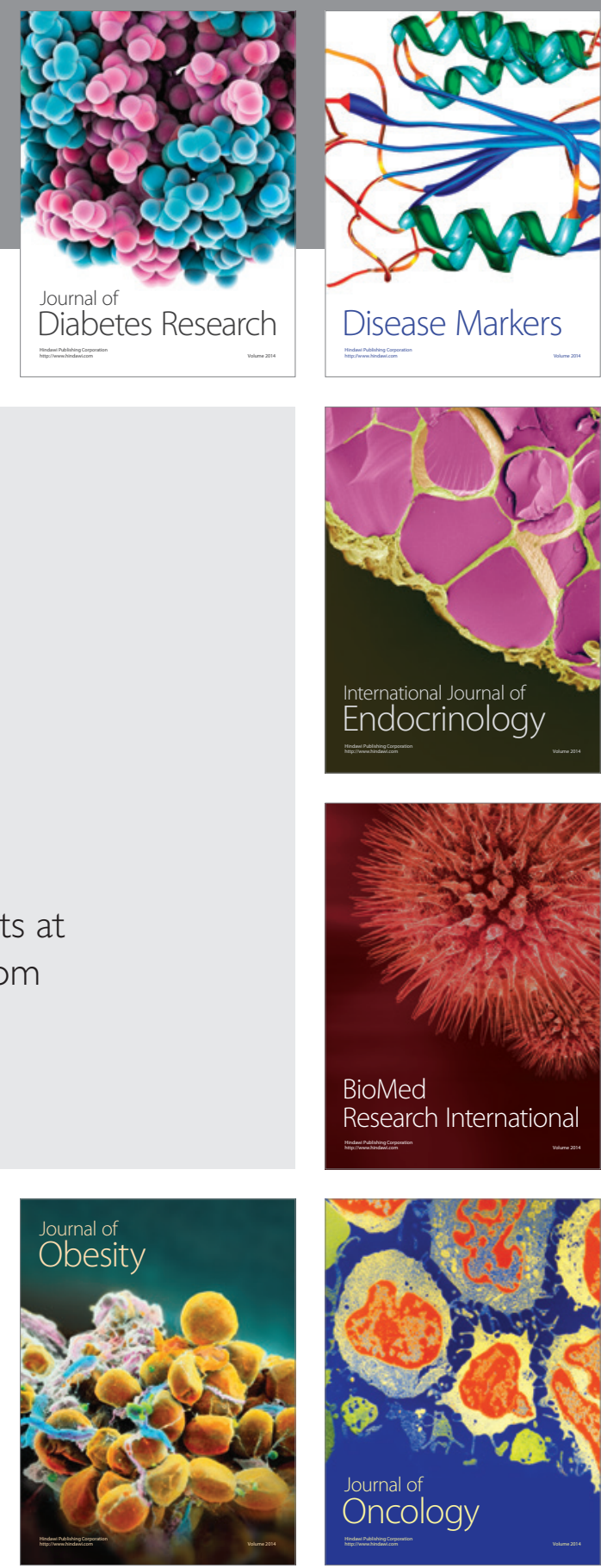

Disease Markers
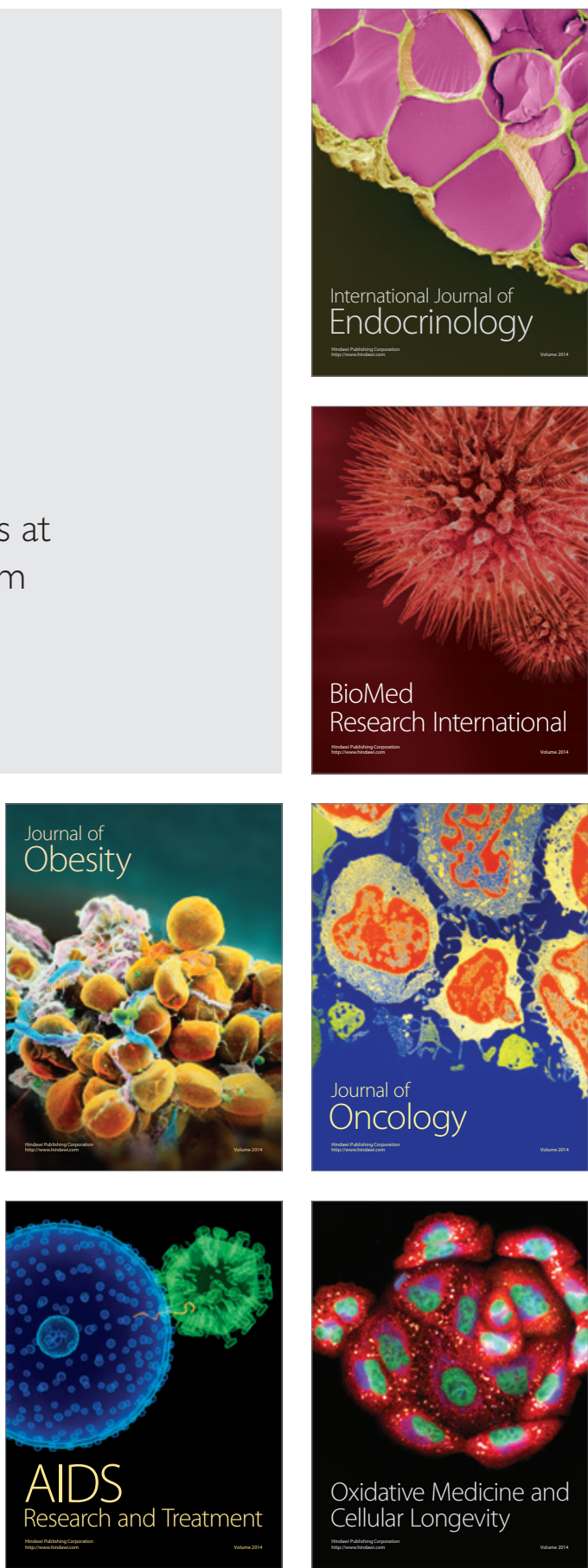